\title{
Dynamic compression of toughened epoxy interlayers in adhesively bonded aluminium laminates
}

\author{
I.G. Grouch, L.J. Greaves, C. Ruiz and J. Harding \\ DRA (Chertsey), Chobham Lane, Chertsey, Surrey, KTI6 OEE, U.K.
}

Resumé: Les lamelles d'aluminium lié avec de la matière adhésive sont une famille de materiaux lamellés hybrides avancés dont les qualités sous impact adaptables sont fortement influencé par le comportment sous pression dynamique des couches intercalaires de résine epoxyde mou. La nature viscoplastique de l'Hysol 9309.3 a été completement characterisee, et une equation CowperSymonds modifiée a été developpé afin de décrìre ses proprietés d'écoulement. Cet équation de résistance a été incorporé dans le logiciel DRA-DYNA-2D et utilisé pour faire les simulations numériques des essais de perforation balistique.

\begin{abstract}
Adhesively-Bonded Aluminium Laminates represent a family of advanced hybrid laminates whose tailorable impact properties are strongly influenced by the dynamic compresssive behaviour of the soft epoxy interlayers. The viscoplastic nature of Hysol 9309.3 has been fully characterised and a modified Cowper-Symonds equation developed to describe its flow properties. This strength equation has been implemented into DRA-DYNA-2D and used to perform numerical simulations of ballistic perforation tests.
\end{abstract}

\section{INTRODUCTION}

Adhesively-Bonded Aluminium Laminates (ABALs) are a class of advanced hybrid composites which offer an opportunity to tailor the energy-absorbing characteristics of lightweight materials subject to direct impact from high velocity projectiles. Against blunt fragments their penetration resistance depends upon a number of key failure mechanisms. Of those identified [1-4], independent shear of the outermost metallic layer is essential if the transverse crack is to be arrested and a low-energy, plugging failure avoided. Figure 1 illustrates the first stage of this penetration process. This independent shearing event is controlled by the ratio of "allowable" through-thickness compressive strain to ply thickness. The former must be larger and is favoured by using compliant interlayers of low modulus materials and relatively thin plies. This key mechanism depends, therefore, upon the balance between the dynamic compressive properties of the soft interlayer, the transverse shear strength of the metallic plies and the geometrical relationship between the two component parts of the laminate.

Previous through-thickness, Constrained Compression Tests (CCTs) of a series of ABALs of varying adhesive interlayer thickness [2] illustrated that a critical minimum thickness was required to guarantee independent shearing. However, these quasi-static simulation tests were not able to reveal the true balance of mechanisms involved in every impact case. It became highly necessary, therefore, to understand, describe and model the compressive deformation of the adhesive interlayer under a range of impact conditions. 


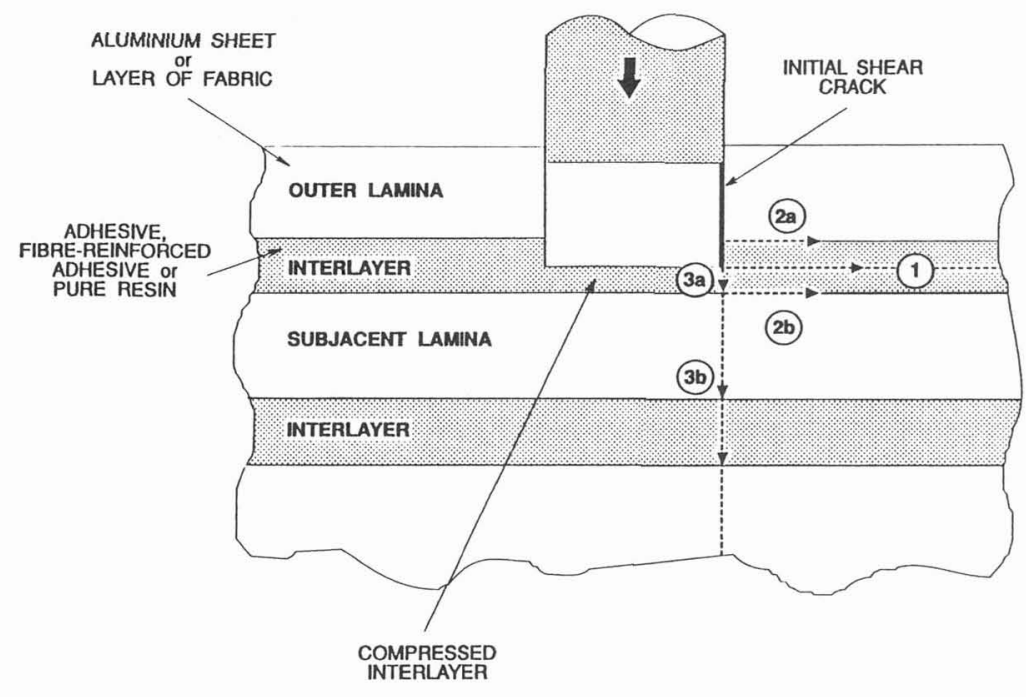

(1) COHESIVE DELAMHNATION

(2) ADHESIVE DELAMINATION

(3) SHEAR CRACKRLLUG FORMATON

\section{MATERIALS AND TEST TECHNIQUES}

The adhesive selected was EA 9309.3 (NA) supplied by Dexter-Hysol. This is a two-part paste epoxy, rubber-toughened, containing glass ballotini beads, and having a stated compressive strength of 52MPa at room temperature. Bulk samples of the adhesive were made by mixing, evacuating, and then extruding the resin into syringes $9 \mathrm{~mm}$ in diameter. The adhesive was then cured by standing at room temperature for 24 hours, followed by 8 hours at $50^{\circ} \mathrm{C}$. Cylindrical test samples were then simply cut to required lengths $(1$ to $8 \mathrm{~mm})$. The measured mean density of the specimens was $1210 \mathrm{~kg} / \mathrm{m} 3$ and the glass transition temperature was given as $80^{\circ} \mathrm{C}$, for this state of cure.

Compression tests on a series of cylindrical samples of bulk adhesive were carried out over a range of test temperatures $\left(-60\right.$ to $\left.+20^{\circ} \mathrm{C}\right)$, strain-rates $\left(10^{-3}\right.$ to $\left.10^{+4}\right)$ and specimen geometry $(\mathrm{L} / \mathrm{D}=0.11$ to 0.89 ). Quasi-static and intermediate tests were carried out using an hydraulic machine of variable crosshead speed. The high strain-rate tests were performed using a standard, compression, $15 \mathrm{~mm}$ diameter, Split Hopkinson Pressure Bar with impact velocities ranging from 7 to $22 \mathrm{~m} / \mathrm{s}$.

\section{EXPERIMENTAL RESULTS}

True stress - natural strain curves were derived from each test and a corresponding flow stress determined. Effects of densification were ignored and plastic deformation of the adhesive samples was assumed to occur uniformly. The strain-rates quoted are those recorded at the determined flow stress.

First the effects of specimen geometry were examined and found to significantly affect the measured flow stress (see Figure 2). After normalising for an increase in strain-rate with a decrease in specimen length the flow stress was seen to be affected by aspect ratio. This is believed to be a thin-film effect caused by a change in plastic constraint. For subsequent tests the length of the sample was fixed at $8 \mathrm{~mm}$.

Further series of tests revealed that the flow properties of the epoxy adhesive were very sensitive to both strain-rate and test temperature. Figures 3 and 4 illustrate that the flow stress can double over four decades of strain-rate or an $80^{\circ} \mathrm{C}$ change in temperature. Attempts to measure changes in moduli were not successful so the compressive modulus of the epoxy was taken to be independent of strain-rate and, in our following calculations, to have a value of $1.7 \mathrm{GPa}$. 


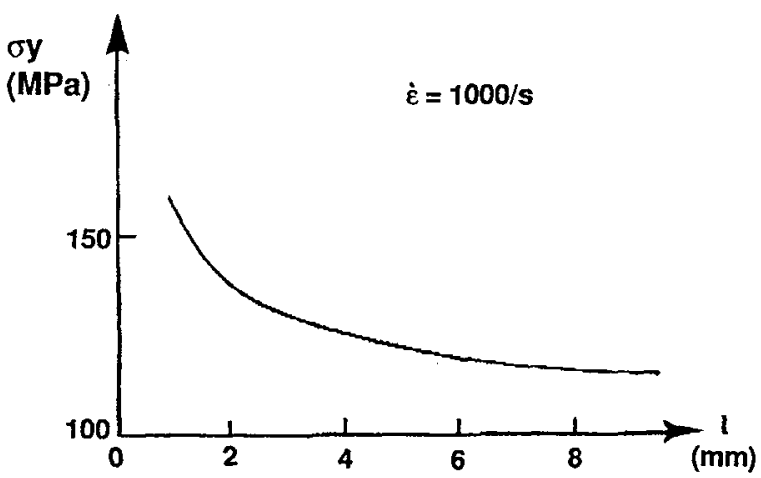

Figure 2: $\quad$ Effects of specimen length on flow stress at $20^{\circ} \mathrm{C}$

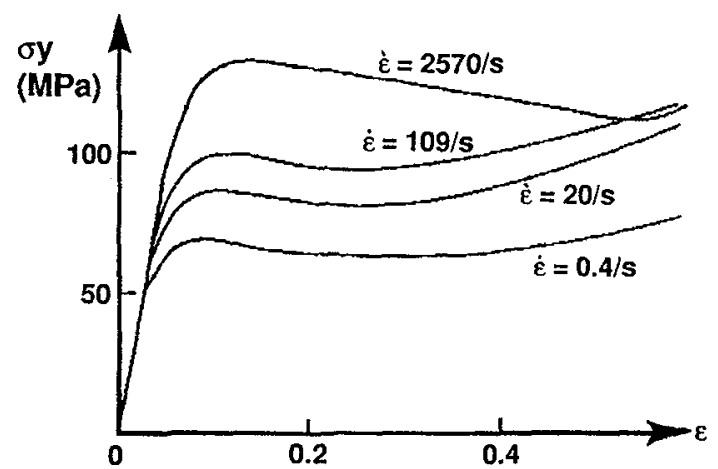

Figure 3: $\quad$ Effects of strain-rate on flow propertes at $20^{\circ} \mathrm{C}$

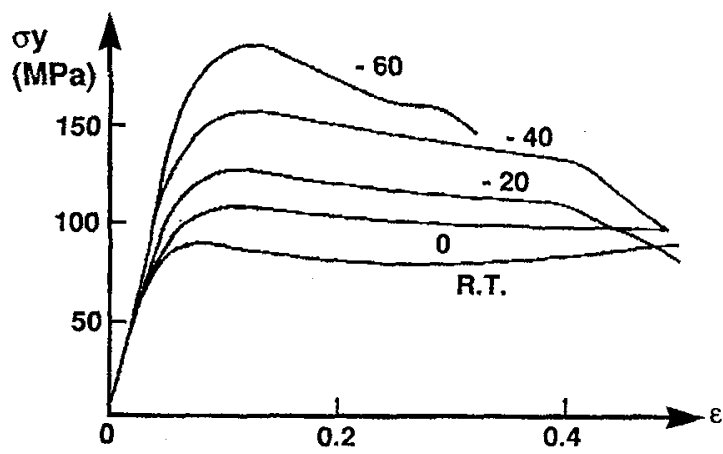

Figure 4: Effect of Test Temperature on flow properties at a strain-rate $=10^{-3}$

\section{CONSTITUTIVE MODEL DEVELOPMENT}

Based upon the von Mises criterion, the associated flow rule and a rate dependent strain hardening rule, the relationship between representative stress and strain after onset of yielding was assumed to be of the Cowper-Symonds form [5] and an empirical fit to all the experimental data was carried out. The equation was modified to account for the test temperature dependance and was:

$$
\sigma_{y}=\left[\sigma_{o}+C_{1} \varepsilon_{p}{ }^{x}\right]\left[1+\left(C_{2} \dot{\varepsilon}_{p}\right)^{n}\right] \cdot\left[\alpha+\beta T+\gamma T^{2}\right]
$$

Equation (1)

where $\varepsilon_{\mathrm{p}}$ and $\varepsilon_{\mathrm{p}}$ are the plastic strain and strain rate respectively.

For Hysol 9309.3 the corresponding values were determined to be: $\sigma_{0}=55 \mathrm{MPa}, \mathrm{C}_{1}=7.96 \mathrm{MPa}, \mathrm{C}_{2}=0.00286$, $\mathrm{n}=0.182, \alpha=9.89, \beta=-0.0554$, and $\gamma=0.0000841$. For polymeric systems it is assumed that $\mathrm{x}=1$.

This new strength model has been implemented within DRA-DYNA and used to carry out detailed numerical simulations of the Constrained Compression Test and ballistic impact events. 


\section{NUMERICAL SIMULATIONS}

Two ABALs, L28 and L9 from previous work [2,4] were modelled. Both contained six plies of 1.02mm thick 7075-T6 aluminium alloy sheet bonded together with the Hysol 9309.3 epoxy. L9 has a thin adhesive interlayer $(0.056 \mathrm{~mm})$ whilst $\mathrm{L} 28$ has a relatively thick interlayer of $0.462 \mathrm{~mm}$. In L28 the first aluminium ply had been shown to shear independently in a CCT and in a ballistic impact: in L9 the first ply did not shear in the CCT and the laminate had failed by plugging in ballistic impact [4].The Constrained Compression Tests were modelled using NIKE-2D in order to study the effects of adhesive thickness upon through-thickness stress-strain behaviour. In this case, a simple elastic-plastic-linear work hardening model was used for both the aluminium and the epoxy. Figure 5 shows that the general behaviour was reasonably well simulated. However, numerical difficulties prevented the solution for L28 progressing to the point where shearing of the outer layer occurred.

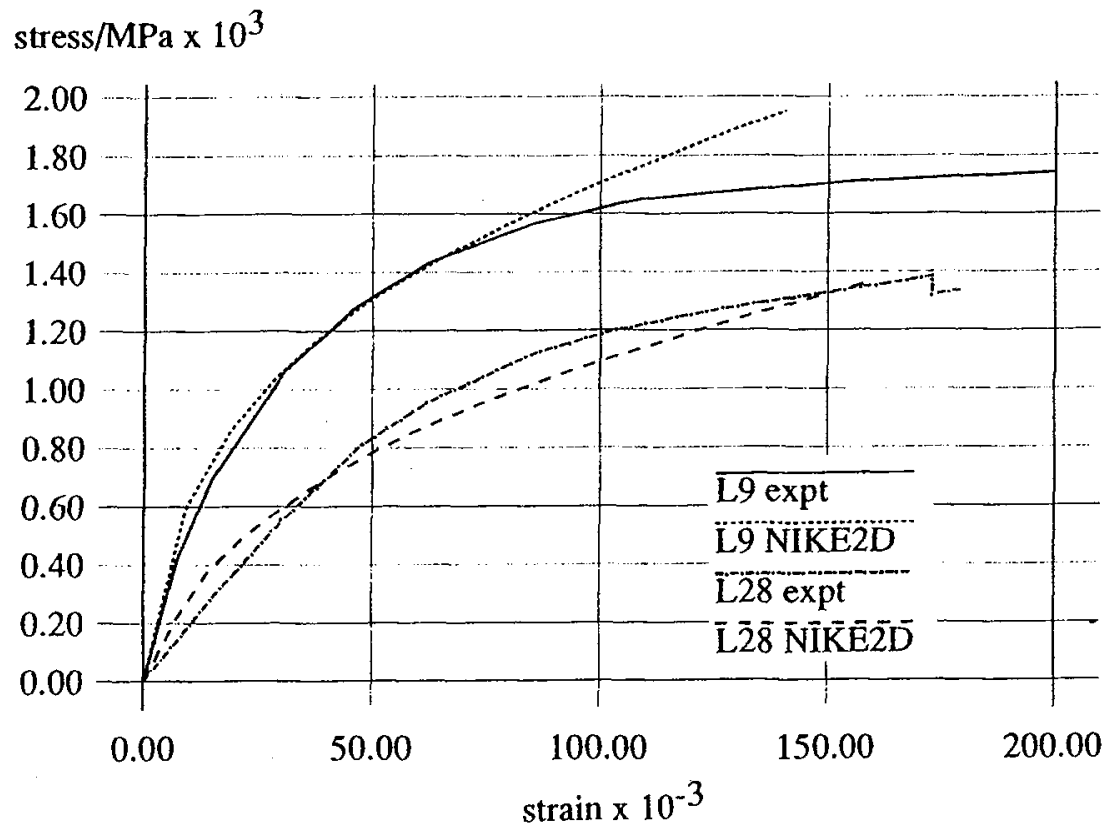

Figure 5: $\quad$ NIKE-2D results for Constrained Compression Test of L9 and L28 6-ply ABALs compared with experiments $[2,4]$

The ballistic impacts were modelled using DRA-DYNA-2D, incorporating the modified Cowper-Symonds equation for Hysol and retaining the same model for aluminium used in NIKE-2D. In the first aluminium ply, failure was modelled by using an erosion algorithm, which deletes an element if the effective plastic strain exceeds a critical value. In the other plies, a spall failure algorithm was used which reduces the tensile and shear strength of an element to zero if a stress based failure criterion is met. For comparison, both laminates were modelled using a non-rate-dependent model for the epoxy using a quasi-static value for its flow stress. The projectile was a blunt steel cylinder impacting at velocites used in the selected experiments (from 150 to $350 \mathrm{~m} / \mathrm{s}$ ).

Figure 6 shows output data of projectile velocity as a function of time for both L9 and L28: neither are seen to arrest the projectile but there are clear differences in decelaration characteristics. The top two lines illustrate the difference that the Cowper-Symonds model has made in retarding the projectile. This effect is not quite so noticeable with the thin interlayered ABAL, L9. However, initial decleration is more rapid with the L9 ABAL (presumably an effect related to density and wave speeds in both laminates) but the L28 laminate certainly has more arresting power over the projectile (compare the lower two curves which commence at the same impact velocity of $189 \mathrm{~m} / \mathrm{s}$ ). 


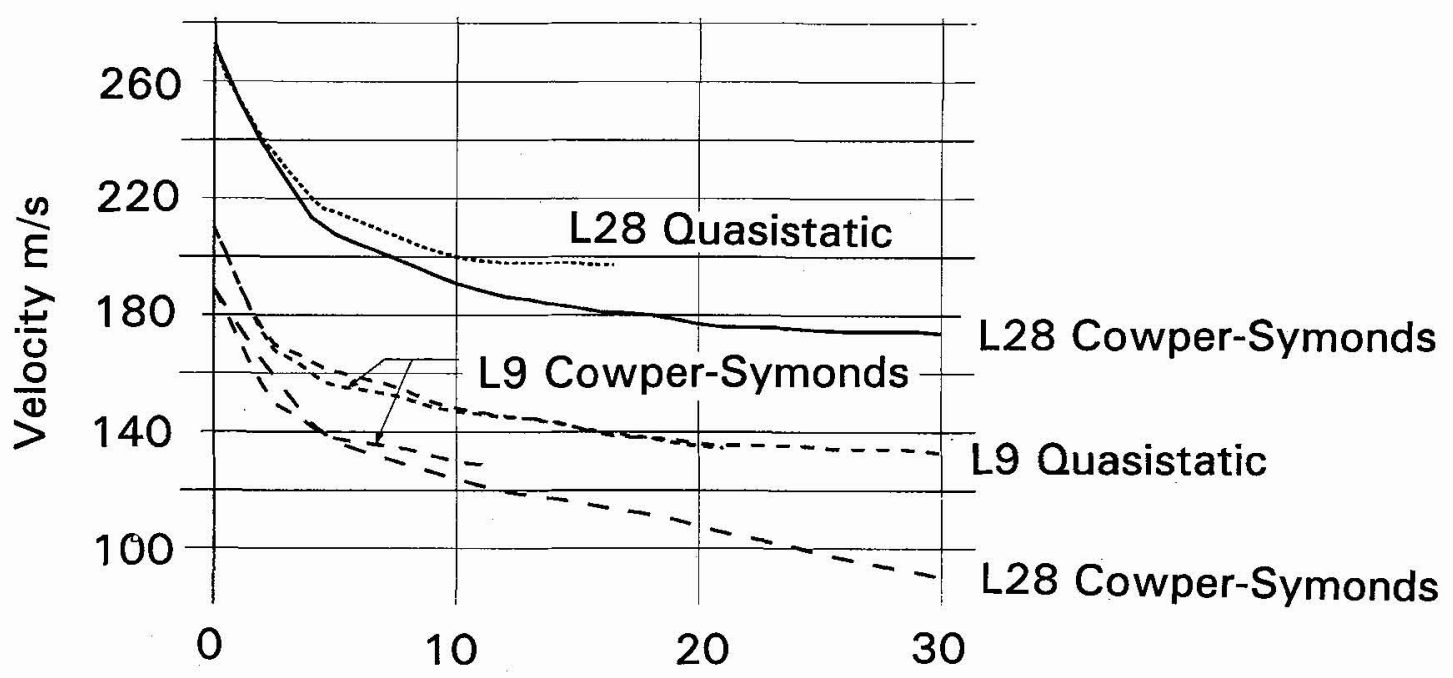

Time $\mu$ s

Figure 6: DRA-DYNA-2D plots of projectile velocity versus time for partial penetrations of blunt projectile into L9 and L28 ABALs.

Figures 7 and 8 show the deformations of the two targets during impacts at $189 \mathrm{~m} / \mathrm{s}$. Our postprocessor, ORION, is not able to show directly which elements have failed. Instead, these figures show fringes of maximum principal strain. The red areas show where this parameter exceeds 0.12 , the tensile ultimate elongation of the aluminium, indicating that failure has occurred. Adhesive failure can be inferred from the widening of the adhesive (white) layers. In L9, a shear crack is seen to propagate from the edge of the projectile, producing a plug slightly larger than the projectile, thus simulating what is observed in
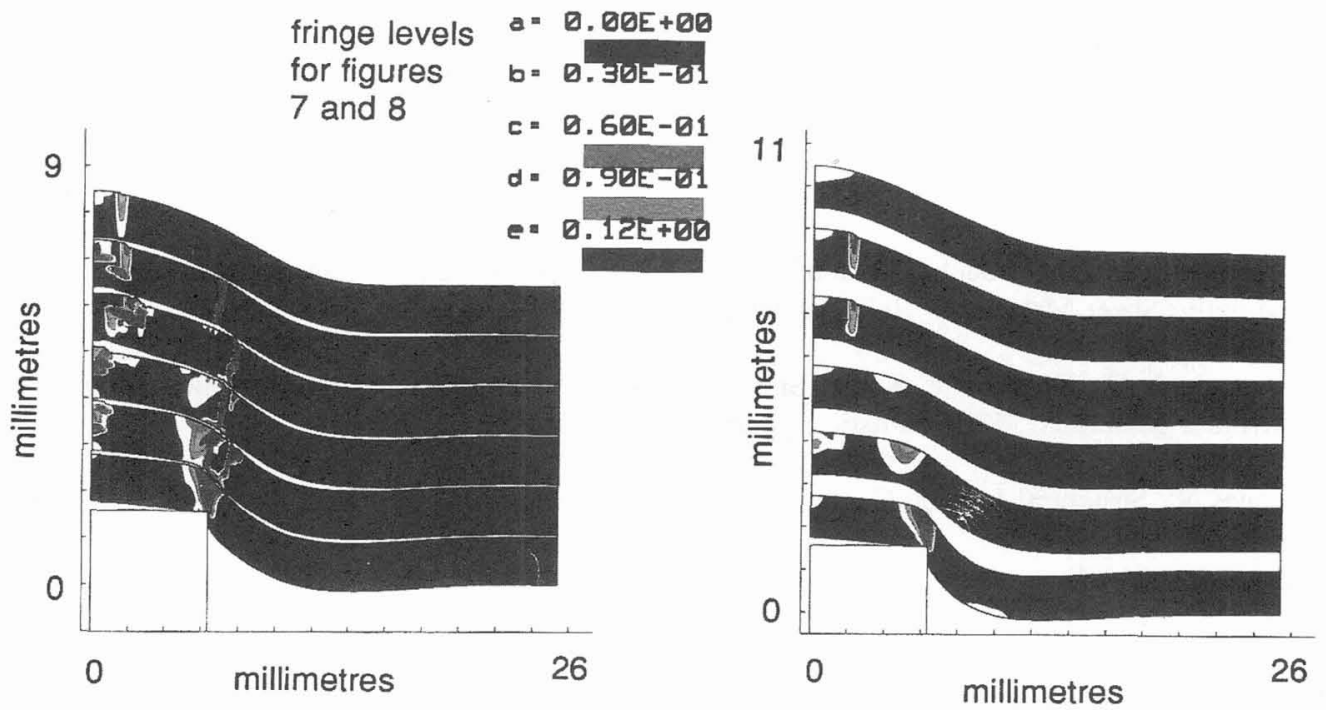

Figure 7: DRA-DYNA output of maximum principal strain for aluminium layers of ABAL L9

Figure 8: DRA-DYNA output of maximum principal strain for aluminium layers in L28 
experiment. It also shows significant spall failures near the axis of symmetry, which did not happen in experiment. In L28 the initial shear crack does not propagate although the exact behaviour depends on the impact velocity. In the case shown, cracks are developing in plies 4 and 5 in a mode akin to scabbing. The ultimate perforations of L.28 in our models have been complex, involving the ejection of discs of aluminium with diameter smaller than the projectile. Spalling failures were not observed in practice when using 7075-T6 aluminium sheet.

\section{DISCUSSION}

The temperature dependence and strain-rate sensitivity of Hysol 9309.3 have been quantified and an improved description of this epoxy adhesive has led to a better understanding of its role in an AdhesivelyBonded Aluminium Laminate. Our current ability to numerically model these laminates has heightened our understanding of this complex impact event even further. Nevertheless considerable deficiencies still exist . The DRA-DYNA simulations revealed that the maximum strain-rate in the epoxy was $5 \times 10^{+5}$ in the L28 laminate and $4 \times 10^{+6}$ in L9, compared to about $10^{+4}$ in the SHPB tests - extrapolation of existing data to $10^{+6}$ is questionable since thermal softening effects may start to appear in reality. Further tests of both laminating resins and epoxy adhesives, using a fast-response infra-red detector to record thermal histories, are currently underway.

General deficiencies in numerical codes, in not treating failure correctly, is limiting further deeper investigations of these advanced hybrid laminates. At present too many arbitrary decisions need to be made about failure criteria and the use of the erosion algorithm to simulate a cracking failure may be susceptible to significant energy errors in other impact problems. Two messages emerge from this work: firstly that material property data is required over an even wider range of strain-rates and secondly that improved methods of modelling failure are essential.

\section{References}

[1] Crouch, I. G, "Adhesively-Bonded Aluminium Laminates - their future as energy-absorbing, structural materials", MECH '88 Congress on New Materials and Processes for Mechanical Design, Brisbane, May 1988, p.21.

[2] Crouch, I. G and Woodward, R. L., "The Use of Simulation Techniques to study the perforation mechanisms in laminated metallic composites", Int. Conf. Mech. Prop. Materials at High Rates of Strain, Oxford, 1989, pp.481-488.

[3] Woodward, R. L., Crouch, I.G. and Tracey, S. R., "The response of Homogeneous and Laminated Metallic Sheet Material to Ballistic Impact, DYMAT '91, October 1991, C3-277.

[4] Crouch, I. G., Greaves, L. J. and Simmons, M. J., "Compression Failure Modes in Composite Armour Materials", 12th Ballistic Symposium, San Antonio, 1990.

[5] Jones,N., Structural Impact, Cambridge University Press, 1989

\section{Acknowledgements}

The authors are thankful for the contribution made by Dr. Yiren Xia during his time in the Engineering Department at Oxford University and to Mr. Phil Webb for carrying out most of the mechanical testing. 